DOI 10.37882/2223-2982.2020.08.38

\title{
К ВОПРОСУ О РОЛИ ВЕРБАЛЬНЫХ И НЕВЕРБАЛЬНЫХ СРЕДСТВ ПРИ РЕАЛИЗАЦИИ КАТЕГОРИИ ОБРАЗНОСТИ В ЭЛЕКТРОННОМ НАУЧНО-ПОПУЛЯРНОМ ТЕКСТЕ С НЕВЕРБАЛЬНЫМ КОМПОНЕНТОМ
}

\section{ON THE ROLE OF VERBAL AND NON-VERBAL MEANS IN THE IMPLEMENTATION OF THE CATEGORY OF IMAGERY IN AN ELECTRONIC POPULAR SCIENCE TEXT WITH A NON-VERBAL COMPONENT}

\section{N. Hristoforova}

Summary: The article analyzes the peculiarities of implementing the category of imagery in an electronic popular science text, taking into account its verbal and non-verbal components. Imagery is considered as a way to conceptualize reality.

A text with a nonverbal component has special requirements for the use of verbal means of creating imagery, since they must meet the semiotic codes of other levels (drawing, color, font, etc.). In addition to the main functions - to promote understanding of the text, attract and hold the reader's attention - the means of creating imagery are used as means of text compression.

The analysis is based on the texts of electronic versions of the publications «Bild der Wissenschaft», "Spiegel», «Focus», "GEO».

Keywords: imagery, popular science text, non-verbal component, verbal component, means of creating imagery.

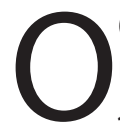

бращение к образности представляется одним из наиболее интересных и перспективных направлений. Образность восприятия играет определяющую роль в жизни человека и может рассматриваться как способ восприятия действительности [1]. В когнитивной лингвистике понятие образности является одним из основных при описании процессов смыслообразования [2]. Образные слова и выражения обладают собственными ассоциациями. Понятие образности изучают философия, литературоведение, логика, психология, лингвистика. Независимо от различных видений и определений понятия, все отрасли науки рассматриваются как способ познания мира.

Интерес к изучению взаимодействия вербального и невербального компонентов в языке и оживлённое развитие средств массовой информации привели к более тщательному изучению текстов с невербальной состав-
Христофорова Наталья Игоревна

к.фрилол.н., доцент, ФГБОУ ВО «Московский авиационный институт (национальный исследовательский университет», г. Москва n_khristoforova@mail.ru

Аннотация: Статья посвящена анализу особенностей реализации категории образности в электронном научно-популярном тексте, учитывая его вербальные и невербальные составляющие. Образность рассматривается как способ концептуализации действительности.

Текст с невербальной составляющей предъявляет особые требования к применению вербальных средств создания образности, т.к. они должны соответствовать семиотическими кодами других уровней (рисунок, цвет, шрифт и т.д.). Кроме основных функций - способствовать пониманию текста, привлечь и удержать внимание читателя - средства создания образности используются как средства компрессии текста.

Анализ проведен на материале текстов электронных вариантов изданий «Bild der Wissenschaft», «Spiegel», «Focus», «GEO».

Ключевые слова: образность, научно-популярный текст, невербальный компонент, вербальный компонент, средства создания образности. ляющей, в том числе, научно-популярного текста. Одним из ярких способов предоставления информации в тексте и в глобальной сети интернет является научно-популярный текст, относящийся к типу текстов с невербальной составляющей. В научно-популярном тексте широко используются средства создания образности в языке. Основной функцией научно-популярного текста с невербальной составляющей является информирование читателя-неспециалиста. Однако именно образность способствуют максимально полному и выразительному описанию в понятной для читателя-неспециалиста форме сложных научных теорий, результатов исследований, открытий. Образность - сложная и многозначная категория, трактуемая по-разному благодаря разному восприятию понятия 《образ〉. Эти различия объясняются его двойственностью: образность бывает языковая и авторская. Образность свойственна словам и является элементом семантики слова; а образный строй текста - сво- 
еобразная форма выражения авторского замысла. При этом использование образных средств зависит от автора, его видения излагаемой информации, ассоциативного мышления и способности к образному описанию действительности. Отметим, что один и тот же «образ в тексте может реализовать сразу несколько интенций. Трактовка образов связана с глубиной читательского восприятия, то есть зависит от читательской компетенции» [3]. Задача автора научно-популярного текста - максимальная точность, логичность и однозначность изложения. При этом текст должен быть привлекательным, интересным и понятным читателям-неспециалистам, с этой целью термины часто заменяются образами, близкими читателю. Отметим, что употребление образов - не просто способ выражения того, что обычно выражается через термины: нередко содержание, которое передаётся образными средствами, нет возможности адекватно передать через термины. В таких случаях велико значение интуиции и образного мышления автора текста, и это отражается в образном употреблении слов. «Образность - изобразительность речи, под которой понимается такая степень ее предметной конкретности, благодаря которой содержание речи воспринимается преимущественно через чувственные... представления» [4]. «Образность - это не «созначение», а существенный признак самого значения, способ представления значения» [5].

В тексте образность можно рассматривать не только на уровне отдельного слова, но и в словосочетании, предложении, строфе, абзаце, тексте. К средствам создания такой образности относятся метафоры, символы, аллегории, сравнения, аллюзии, гиперболы, иронии, олицетворения, метонимии и другие тропы, что делает язык текста более эмоциональным и в то же время более понятным. Читатель лучше понимает авторское восприятие описываемого исследования или открытия, его умозаключения, саму суть события из области науки, которое описывается в форме, доступной широкому кругу читателей-неспециалистов с помощью образных средств, имея целью популяризировать последние достижения исследователей.

Образное словоупотребление обращает внимание читателя на явления и предметы, поддающиеся чувственному восприятию, и имеющие общие признаки с явлениями и предметами, которые являются новыми для читателя, и, таким образом, повышает возможности читателя к познанию, а, значит, и расширяет его кругозор. Научное мышление исследователей находит отражение в образной речи автора научно-популярного текста, а благодаря ей, в сознании читателя-неспециалиста.

В научно-популярном тексте образность выполняет следующие функции:

— оценочную (она связана с функцией воздействия на читателя, формирует обобщающую оценку информации, представленной в тексте);

- рекламную (как средство привлечения и удержания внимания читателя, как вариант - части текста, играющие роль рекламных, выделены);

- разъяснительную (на основании возможности отразить абстрактное понятие через конкретные образы);

- описательную (основана на возможности наглядного объяснения с помощью сравнения);

- компрессии информации (возможность передачи содержательно-фактуальной и содержательноконцептуальной информации в краткой и упрощённой форме).

При включении в научно-популярный текст образных средств часто наблюдается сочетание и взаимодействие нескольких их функций, причём одна из них обычно является основной.

Применение образных средств в научно-популярных текстах часто обуславливается стремлением автора выразить суть информации, второстепенной для текста как можно короче. Отметим, что на фоне употребления слов с низкой степенью экспрессивности образные фразеологизмы воспринимаются как повышенно экспрессивные. Самый большой интерес при рассмотрении образности научно-популярного текста представляет собой индивидуально-речевая образность - в ней максимально отчётливо проявляется способность автора к метафоризации действительности. Использование образных средств основывается на требованиях, которые предъявляются научно-популярным текстам - упрощение представления сложной информации с целью облегчения её восприятия и повышения эффективности воздействия. Оригинальные образные средства обладают высокой степенью воздействия, хотя для их понимания требуется больше времени. Понимание метафоры происходит быстрее, но из-за меньшей степени экспрессивности по сравнению с оригинальными (авторскими) образными средствами она представляет собой менее эффективное средство воздействия. Особенности образного словоупотребления в научно-популярных текстах заметны при сопоставлении такого использования слов с употреблением терминов. В научно-популярном тексте на первый план выдвигается второстепенный вариант значения слова, а в стилистическом плане это приводит к появлению у слова новых, ранеее не свойственных ассоциаций, а это важно для процесса формировании у читателя представления о новых для него предметах и явлениях.

Количество узуально-речевых образов в научно-популярных текстах меньше, чем индивидуально-речевых образов, которые являются результатом индивидуального речевого творчества авторов текстов. Это объясняется задачей автора текста: донесение сложной научно- 
технической информации до как можно большего числа читателей. Один из способов решения этой задачи - создание новых, неожиданных образов. Многие узуальноречевые образы, которые считаются избитыми, шаблонными, утратившими свою изобразительную ценность в художественной речи, воспринимаются при чтении научно-популярного текста как экспрессивные выражения. Например, в интервью с известным энтомологом [6] употребляются профессиональные термины из области авиации, аэродинамики:

Bei Fliegen wiederum ist das zweite Flügelpaar umgebaut zu winzigen Sensoren, die hochpräzise Flugmanöver erlauben -У мух вторая пара крыльев реконструирована в крошечные сенсоры/датчки, которые позволяют совершать высокоточные фигуры пилотажа/менёвры в полёте/авиационные манёвры.

Там же употребляется термин «модуль», использующийся во многих областях науки и техники (технология, конструирование, авиация, космонавтика, информационные технологии и т.д.):

Die erwachsenen Tiere sind in drei Teile gegliedert. Vorn sitzt der Kopf. An den schließt sich der Brustkorb an. Und an dem wiederum hängt der Hinterleib. Wie Module können die einzelnen Einheiten je nach Lebensweise abgewandelt werden. - Взрослые особи делятся на три части....Подобно модулям отдельные элементы могут видоизменяться в зависимости от образа жизни.

Автор текста использовал термины в отношении другой области знаний - изучения насекомых, их особенностей и возможности использования этих особенностей в медицине, создав таким образом новый, экспрессивный образ, вызывающий интерес читателя благодаря своей неожиданности.

Образность заметна и в невербальной составляющей текста, это:

- Цветная фотография равнокрылых стрекоз в необычном ракурсе - глаза стрекоз находятся на уровне глаз читателя, то есть, неожиданно для него оказывается, что глаза эти большие относительно размеров тела, а ещё их можно назвать огромными и удивительными - они полупрозрачные, зелёно-голубые, и, что самое интересное, будто бы внимательно вглядываются в читателя. Происходит неожиданный «контакт», непривычное общение «глаза в глаза» - не каждому человеку, тем более неспециалисту в энтомологии, приходило в голову заглянуть в глаза насекомому. Фотографию можно при желании увеличить и рассмотреть подробнее. Возможно, благодаря этой фотографии, кому-то из читателей стрекозы покажутся внеземными существами. Динамичный образ дополняет подпись (шрифтом другого цвета, что отделяет её от основного текста), указыва- ющая, насколько сложны эти, казалось бы, «просто» насекомые:

Auch Insekten (hier Kleinlibellen) haben ein Immunsystem, um sich gegen Krankheitserreger zu wehren. Bei manchen Sechsbeinern hat man neuartige antibiotisch wirksame Stoffe gefunden. - Иммунная система защищает насекомых от возбудителей болезней. У некоторых насекомых нашли в организмах вещества, действующие как антибиотики новых видов.

- Цветная фотография (с возможностью увеличения) бабочки на цветке в том же необычном ракурсе - на уровне глаз бабочки. Происходит новый неожиданный контакт читателя-неспециалиста с насекомым на уровне глаз, на это раз довольно больших чёрных глаз, которые тоже могут показаться глазами (или неглазами) некоего инопланетного существа. Чёрные глаза бабочки примерно такого же размера, что и пятна на её крыльях. Образ разъясняется и дополняется подписью с той же особенностью - шрифт другого цвета отделяет её от остальной части текста: Insekten sind Meister der Anpassung: Je nach Lebensweise haben etwa Schmetterlinge ausladende Flügel entwickelt, Bienen schmalere, häutige, und Flöhe haben ihre Flügel ganz verloren - Насекомые - мастера адаптации: благодаря образу жизни у бабочек развились широкие крылья, у пчёл - более узкие и плёнчатые, а блохи утратили крылья.

- Цветная фотография (с возможностью увеличения) подёнки обыкновенной сделана с иного ракурса - сверху, но крупным планом. Читатель уже не «контактирует» с насекомым «на уровне глаз», он находится немного выше, хотя и недостаточно далеко, чтобы не заметить, какое это интересное существо. Назвать это насекомое просто красивым и загадочным мало, что подтверждает подпись под фотографией, выполненная таким же цветом шрифта, что и другие:

Sechsbeiner - hier ein Fadenhaft - bergen Millionen unbekannter Substanzen, die auch für uns Menschen nützlich sein können. Erst einige Tausend haben Forscher wie Vilcinskas ausgewertet - Шестиногие (надкласс членистоногих, в который входят насекомые) - здесь подёнка обыкновеная - таят в себе миллионы неизвестных веществ, которые могли бы принести пользу и нам, людям. Такие исследователи, как энтомолог, у которого берется интервью, изучили всего лишь пару тысяч этих существ.

- Завершающий снимок - чёрно-белая фотография исследователя, на руке которого сидит жук (фотографию можно увеличить и рассмотреть подробно). Читатель «вернулся» в мир людей, он общается с исследователем, одним из ведущих специалистов в области изучения насекомых и основателем первого в мире института биотехноло- 
гии насекомых. Благодаря фотографии и сопровождающей её подписи возникает реальный образ исследователя, у которого берут интервью:

Prof. Andreas Vilcinskas, Jg. 1964, ist einer der führenden Insektenforscher Deutschlands und hat in Gießen das weltweit erste Institut für Insektenbiotechnologie gegründet.

«Контакт» происходит уже на уровне глаз собеседников - двух людей, один из которых может рассказать другому о насекомых много неожиданного, нового и очень интересного. Подчеркнём, что эта фотография чёрно-белая - читатель как бы совершил путешествие в мир насекомых, а потом возвращается в мир повседневности, документальности.

Рассмотрим пример индивидуально-речевой образности в тексте об исследовании чёрных дыр [7]. Образ используется уже в названии и создаётся употреблением слова «Herzschlag» Обычно это слово употребляется в контексте медицины и переводится как «биение сердца», «пульс», «сердцебиение», «сокращение сердца» и др. В данном случае оно использовано для описания процессов, происходящих в чёрной дыре. Чёрная дыра массивный космический объект, и понять суть процессов внутри него достаточно сложно, с другой стороны, читатель-неспециалист наверняка измерял собственное кровяное давление самостоятельно или при помощи специалиста, так что образ для него вполне понятен:

\section{«Herzschlag» von schwarzem Loch wiederentdeckt}

- Слово заключается автором в кавычки, что уже является своеобразным сигналом его нестандартного использования. Название текста можно перевести: «Пульс» чёрной дыры снова обнаружен».

Развитию и пониманию образа способствует и подзаголовок, разъясняющий смысл образа: Astronomen haben ein ungewöhnliches Signal im Weltraum aufgespürt. Es kommt von einem schwarzen Loch und erinnert an einen Herzschlag. - Астрономы уловили необычный сигнал из космоса. Он исходит от чёрной дыры и похож на биение сердца.

В тексте приводится разъяснение исследователей, почему использовано именно это сравнение: внутренние области аккреционного диска чёрной дыры растягиваются и сжимаются, а по времени, проходящему между этими процессами можно судить о величине и структуре материи вокруг чёрной дыры. Это даёт возможность проведения дальнейших исследований:

„Die Hauptidee für die Entstehung dieses Herzschlags ist, dass sich die inneren Bereiche der Akkretionsscheibe ausdehnen und zusammenziehen", sagt Chris Done.... Auf diese Weise könnte Materie schwallartig in das schwarze
Loch fallen. Die Zeit zwischen den "Herzschlägen" kann demnach Auskunft geben über die Größe und die Struktur der Materie in der unmittelbaren Umgebung des schwarzen Lochs... Die Wiederentdeckung biete nun die Gelegenheit, die Natur und den genauen Ursprung des ${ }_{4} \mathrm{Herzschlag}^{\prime \prime}$-Signals genauer zu untersuchen, so die Forscher.

Образ того же ряда, «пульсации» чёрной дыры, создаёт цветное изображение-реконструкция (с возможностью увеличения) чёрной дыры с подписью:

Künstlerische Darstellung eines schwarzen Lochs: Saugt das Massemonster Materie schwallartig ein? - Реконструкция чёрной дыры: правда ли, что монстр огроной массы засасывает материю подобно пульсу/пульсирующими движениями?

В научно-популярном тексте его невербальная составляющая становится семантическим и стилистическим невербальным образом только под влиянием вербальной части текста. Так, например, фотография куриных яиц [8] без вербальной части текста и подписи была бы фотографией, взглянув на которую читатель мог бы подумать о чём угодно и сделать любые выводы, скорее всего не соответствующие содержанию текста.

Текст начинается с обобщающего заголовка, набранного красным шрифтом:

Cholesterinbomben oder Superfood - «Холестериновая бомба или суперфуд». Сейчас широко обсуждается вопрос, что же такое правильное питание, поэтому тема «Крайне вредный продукт или сверхполезный продукт» должна привлечь внимание большого количества читателей.

Ниже тема конкретизируется в заголовке, набранном жирным чёрным щрифтом:

Die Wahrheit über Eier: Wie viele gesund sind und $a b$ wann sie dem Körper schaden. - Правда о яйцах. Сколько штук можно съесть с пользой для здоровья, а когда они уже вредны для организма.

Под ним располагается цветная фотография яиц с подписью, из которой становится ясно, что текст рассказывает о последних исследованиях и полученных данных о пользе и вреде этого продукта:

Wie viele dürfen es sein? Experten empfehlen, in der Regel nicht mehr als drei Eier pro Woche zu essen. Wer gesund und fit ist, hat dabei aber ordentlich Luft nach oben. - Сколько их можно съесть? Как правило, эксперты рекомендуют съедать не более трёх яиц в неделю. У кого нет проблем со здоровьем, может съедать и больше.

Применение образных средств способствует появлению у читателя дополнительных чувственных и интеллектуальных ассоциаций с целью повышения убедительности информации, повышения уровня её усвоения, 
привлечению к ней внимания читателя. Так, название текста, посвящённого археологическим исследованиям [9] указывает на необычный ракурс рассмотрения данных, полученных учёными-палеонтологами:

Kurios: Krokodile auf zwei Beinen - «Это интересно» или «Любопытно»: двуногие крокодилы.

Многие читатели-неспециалисты знают, как выглядит крокодил (видели в зоопарке, по телевизору, в интернете и др.), значит, им известно, что те передвигаются на четырёх конечностях, поэтому ассоциация у читателя-неспециалиста типа: «странно», «непонятно» вполне оправданна, как и желание узнать, что же имел в виду автор.

Далее приводится цветной рисунок-реконструкция (есть возможность увеличения) с поясняющей подписью:

So könnten die zweibeinig laufenden Krokodile ausgesehen haben. - «Так могли бы выглядеть крокодилы, бегавшие на двух ногах».

Читателю-неспециалисту пока что не очень ясно, почему один из древних видов ископаемых животных назвали именно крокодилами, ведь это могли быть предки любого современного существа. Однако краткое объяснение приводится в подзаголовке, выделенном жирным шрифтом:

Vor etwa 110 Millionen Jahren waren im heutigen Südkorea seltsame Wesen auf zwei Beinen unterwegs: kreidezeitliche Verwandte unserer heutigen Krokodile. Das schließen Paläontologen aus Untersuchungsergebnissen von versteinerten Fußspuren. Vergleichbare Abdrücke an anderen Fundorten könnten demnach ebenfalls von den mysteriösen „Zweibein-Krokos" stammen und nicht von laufenden Flugsauriern, wie zuvor vermutet wurde. - «Примерно 110 млн. лет назад там, где находится современная Южная Корея, жили существа, передвигавшиеся на двух ногах: родственники современных крокодилов, которые существовали в меловом периоде. Предположительно, аналогичные отпечатки могут принадлежать «двуногим» крокодилам.

В ходе текста приводятся доказательства правоты исследователей:

Zweibeinig laufende Krokodile wirken fast wie ein Scherz - doch den Wissenschaftlern zufolge ist dies möglich. Denn die verschiedenen Vertreter der Crocodylomorpha besaßen zwar viele gemeinsame Merkmale mit unseren heutigen Krokodilen, aber es gibt auch Beispiele von Arten mit einer ungewöhnlichen Statur. - Вполне возможно, что двуногие крокодилы - не шутка. Тому есть доказательства.

Именно поэтому один из разделов текста называется достаточно экспрессивно: «Ein Krokodil war's!» - «Это был именно крокодил!» В нём приводятся и фотографии исследователей с объединяющей подписью:

Detailaufnahme von drei der Fußspuren. «Подробный снимок трёх отпечатков!

Читатель может поразмышлять и решить, согласиться ли с мнением исследователей, опровергнуть его, опираясь на собственные знания о крокодилах, или подождать новых археологических находок.

В заключение, о категории образности можно сказать следующее: она является одной из основных категорий электронного научно-популярного текста. Указанная категория реализуется максимально полно благодаря сочетанию вербальных и невербальных средств, что способствует повышению эффективности воздействия на читателя, пробуждает и удерживает его интерес к теме на протяжение всего текста, формирует у него оценку прочитанного, соответствующую оценке автора текста, а также способствует совершению читателем действий как вербального, так и невербального плана - от отправки ссылки на текст знакомому или поиска дополнительной информации по теме, рассмотренной в тексте, до пересказа кому-либо содержания текста.

\section{ЛИТЕРАТУРА}

1. Федяева Е.В. Образы сознания как форма познания действительности//Вестник Томского гос. пед. ун-та. 2016. Томск, № 3 (168), с. 73-78

2. Устинова Т.В. Лингвистически опосредованная реконцептуализация исходного сообщения: когнитивные аспекты смыслообразования в поэтическом переводе//Известия Волгоградского гос. пед. ун-та. 2017. Волгоград, № 4 (117), с. 87-94

3. Токарев Г.В. Семиотеческий аспект образности художественного текста//Учёные записки КФУ им. Вернадского. 2018. Симферополь, № 4 (70), с. 187- 196

4. Рыжих М.В. Полимодальность-образность-иконичность//Вестник МГлу. Гуманитарные науки. 2016. Москва, № 19 (758), с. 103- 109

5. Узденова 3.К. Маркированность лексических единиц в полиэтническом аспекте//Проблемы современного педагогического образования. 2018. Ялта, № 60-1, C. 325-328

6. Weiß Bertram, Harf Rainer. Weshalb Insekten biochemische Schatztruhen für die Medizin sind. GE0. 2020 [электронный ресурc] URL: https://www.geo.de/ wissen/22758-rtkl-forschung-weshalb-insekten-biochemische-schatztruhen-fuer-die-medizin-sind (дата обращения: 13.06 .2020 г.)

7. koe/dpa «Herzschlag» von schwarzem Loch wiederentdeckt. Der Spiegel. 2020 [электронный ресурc] URL: https://www.spiegel.de/wissenschaft/weltall/ 
schwarzes-loch-forscher-entdecken-roentgensignal-wieder-das-schlaegt-wie-ein-herz-a-6d4aba2a-b5f1-4fb8-b458-0f3e9934а608 (дата обращения: 10.06.2020 г.)

8. Preuk, Monika. Cholesterinbomben oder Superfood. Die Wahrheit über Eier: Wie viele gesund sind und ab wann sie dem Körper schaden. F0СUS. 2020. [электронный ресурс] URL: https://www.focus.de/gesundheit/ernaehrung/gesundessen/cholesterinbomben-vs-superfood-die-wahrheit-ueber-eier-so-viele-eier-sindgesund-so-viele-eier-duerfen-sie-essen_id_10582790.html (дата обращения: 13.04 .2020 г.)

9. Vieweg. Martin. Kurios: Krokodile auf zwei Beinen. Bild der Wissenschaft. 2020. [электронный ресурс] URL: https://www.wissenschaft.de/erde-klima/kurioskrokodile-auf-zwei-beinen/ (дата обращения: 12.06 .2020 г.)

(c) Христофорова Наталья Игоревна (n_khristoforova@mail.ru).

Журнал «Современная наука: актуальные проблемы теории и практики»

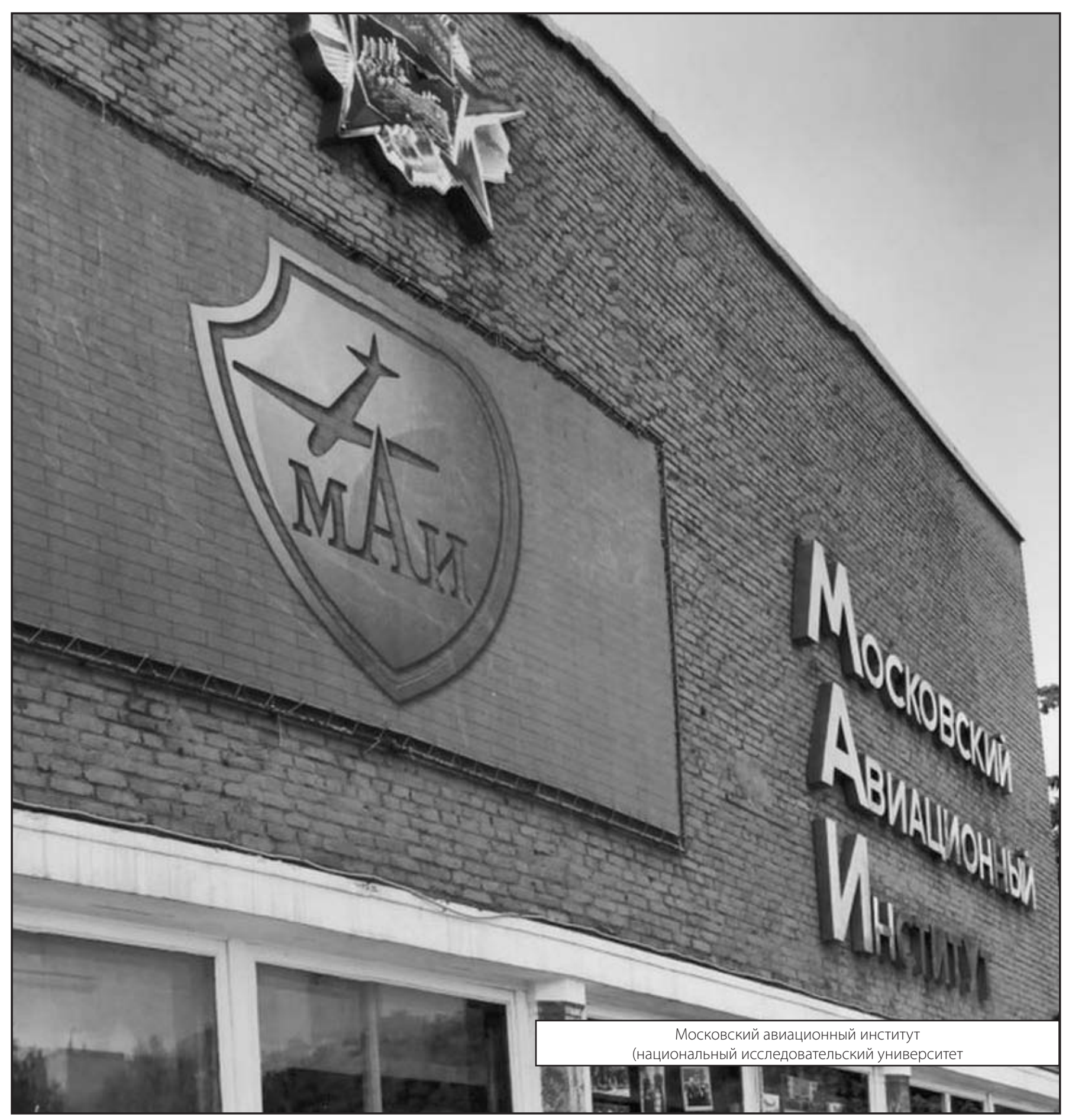

